\title{
The Good and the True (or the Bad and the False)*
}

\section{Daniel Whiting}

The definitive version of this article is to appear in Philosophy, published by

Cambridge University Press. When citing, please refer to the published

version, which will be available from:

http://journals.cambridge.org/action/displayJournal?jid=PHI

\section{$1 \quad$ Truth as good}

According to William James:

Truth is one species of the good, and not, as is usually supposed, a category distinct from good, and coordinate with it. The true is the name for whatever proves itself to be good in the way of belief. (1995 [1907]: 42)

Recent expressions of similar thoughts include:

It is uncontroversial that true belief is epistemically good. (DePaul 2001: 177)

Truth is indeed a property of our beliefs that we value. (Engel 2009: 188)

True beliefs are valuable. (Horwich 2010: 56)

It should be uncontroversial that we do and should value true believing. (Jones 1997:

True belief is valuable. (Kvanvig 2003: xiv)

It is good to believe what is true. (Lynch 2004b: 12)

True belief is desirable. (Schantz 2007: 309)

\footnotetext{
* Thanks to Conor McHugh for detailed feedback on earlier versions of this papers. Thanks also to Jonathan Way, anonymous referees, and audiences at Aberdeen, Lund, Reading, and Southampton for comments on the material and discussion of the issues it concerns.
} 
All true beliefs probably have some intrinsic value simply in virtue of being true.

(Zagzebski 2003: 24)

Numerous other philosophers make similar claims. ${ }^{1}$

Following Lynch (2004a: 499), one might try to capture the thought here with the following evaluative principle:

(TG) For any $p$ : it is good to believe that $p$ if and only if it is true that $p .^{2}$ According to (TG), it is good to believe that Spinoza was Dutch, that Wim Wenders directed Paris, Texas, that camellias enjoy an acid soil, and so on, while it is not good to believe that Leibniz was Irish, that Stanley Kubrick directed The Conversation, that heathers enjoy an alkaline soil, and so on. ${ }^{3}$

It is important to stress that, according to (TG), what is valuable is believing truly irrespective of what is believed. That is, (TG) attributes to true belief contentindependent value. Suppose it matters whether the wheat needs harvesting. If the wheat does indeed need harvesting, it would be a good thing to believe this. While the proponent of (TG) does not deny that believing a certain truth can be good given the importance of having a belief about the relevant subject matter, she claims that, in addition, believing the truth is valuable as such, quite apart from the subject matter.

If (TG) is true, this might tell us something deep and important about truth; indeed, it is commonplace to object to certain theories of truth on the grounds that they do not do justice to or conflict with truth's being valuable. Instead, or in addition, one might think that (TG) reflects something about the essential nature of belief,

\footnotetext{
${ }^{1}$ See David 2005b; Fantl and McGrath 2009: 165-170; Goldman 1986; Loewer 1993; McHugh 2012; Morris1992; Pritchard 2010: 154-155; Putnam 1981; Railton 1994; Riggs 2002.

${ }^{2}$ Not all those cited above explicitly endorse both directions of this biconditional, though many of their comments suggest that they would do so. In any event, the part of (TG) which I shall challlenge, namely, its right-to-left conditional, is the part they explicitly endorse.

${ }^{3}$ The idea that it is good to believe the truth is related to, though distinct from, the idea that the aim or goal of belief is truth. For discussion, see Whiting 2012.

The idea that it is good to believe the truth is related to, though distinct from, the idea that a norm of truth governs belief, such as that one should believe the truth. For discussion, see Whiting 2010.
} 
something which an adequate theory of that psychological state or attitude must accommodate. One might also appeal to (TG) in attempting to account for the source and force of epistemic norms, for example, that one ought to believe what the evidence supports. According to teleological views, which are close to orthodoxy in epistemology, epistemic norms are instructions or rules the following of which promotes or is a means to securing a certain good. If (TG) is correct, that good might be true belief.

In what follows, I shall focus on neither (TG)'s implications nor its explanatory significance. Instead, I shall address the prior issue of whether one should accept the principle in the first place. To anticipate, while I do not deny that it is sometimes, even often, good to believe the truth, I shall reject (TG) - it is not the case that it is good to believe each and any truth, no matter what it concerns. The principal objection to (TG), which I shall introduce below, is familiar from the literature but I shall consider a number of responses to it which have received little, if any, critical attention. The aim is not to demonstrate conclusively that (TG) is mistaken but to muster considerations which speak against it so as to motivate a reassessment of the competing considerations which philosophers offer in its support. In doing so, I shall argue that those considerations do not in fact support (TG) but instead point toward a superficially similar though quite distinct principle, namely:

(FB) For any $p$ : it is bad to believe that $p$ if and only if it is false that $p .^{4}$ According to (FB), it is bad to believe that Descartes was English, that Werner Herzhog directed Down by Law, that magnolias enjoy alkaline soil, and so on, while it

\footnotetext{
${ }^{4}$ I shall assume that, if a proposition is not true, it is false. Nothing in what follows hangs on this. To allow for truth-value gaps, one could simply replace talk of its being false that $p$ with talk of its not being true that $p$. According to the account which results, it is bad to believe a proposition if and only if it is not true.
} 
is not bad to believe that Hume was Scottish, that Hal Hartley directed Henry Fool, that azaleas enjoy acid soil, and so on.

One of the aims of this paper to introduce (FB) and to suggest that it is defensible, at least in the face of the objection considered here. Thus, I shall conclude, there is an interesting asymmetry - deserving of more investigation - between truth and falsity, namely, that while truth is not always good, falsity is always bad. More carefully, while believing the truth does not have content-independent value, believing the false has content-independent disvalue.

(FB) is surprisingly neglected. I know of no work in which it is advanced or considered independently of (TG). Typically both critics and advocates of (TG) either ignore (FB) completely or lump it together with (TG). ${ }^{5}$ Perhaps there is a guiding assumption that the idea that false belief is bad is equivalent to the idea that true belief is good, or at least that they stand or fall together. One of the aims of this paper is to show that these assumptions are mistaken.

\section{$2 \quad$ Preliminary matters}

Before turning to the problems facing (TG), there are some preliminary matters to attend to. First, there are various ways to unpack claims such as that it is good to believe the truth (cf. David 2005a; David 2005b). One can distinguish the following principles according to the scope of the evaluative expressions and quantifiers involved:

$\left(\mathrm{TG}^{1}\right) \quad$ For any $p$ : (it is good to believe that $p$ ) if and only if it is true that $p$.

\footnotetext{
${ }^{5}$ For example, neither Kvanvig (2008) nor Grimm (2008) in their discussions of the idea that true belief is valuable consider the disvalue or otherwise of false belief. Elsewhere, when defending the value of truth, Kvanvig (2003: 38-42), simply does not mention falsity and, in later remarks on what is of value 'from a purely intellectual point of view' (54), refers to 'getting to the truth and avoiding error' only as a package.
} 
$\left(\mathrm{TG}^{2}\right) \quad$ For any $p$ : it is good (to believe that $p$ if and only if it is true that $p$ ).

$\left(\mathrm{TG}^{3}\right) \quad$ It is good (for any $p$ : to believe that $p$ if and only if it is true that p).

In a similar fashion, one can distinguish various versions of (FB).

Since it is true that granite is an igneous rock, it follows from $\left(\mathrm{TG}^{1}\right)$ that it is good to believe that granite is an igneous rock. And since it is false that granite is a sedimentary rock, it follows from $\left(\mathrm{TG}^{1}\right)$ that it is not good to believe this.

Though $\left(\mathrm{TG}^{1}\right)$ might imply $\left(\mathrm{TG}^{2}\right)$, the converse does not hold. According to $\left(\mathrm{TG}^{2}\right)$, what is good is either believing a proposition and that proposition's being true or not believing a proposition and that proposition's not being true, and what is not good is either believing a proposition and that proposition's not being true or not believing a proposition and that proposition's being true. If a subject believes (truly) that Cameron is Prime Minister, it does not follow from $\left(\mathrm{TG}^{2}\right)$ that her so believing is good, any more than it follows that Cameron's being Prime Minister is good.

According to $\left(\mathrm{TG}^{3}\right)$, what is good is believing all and only truths, which is to say nothing whatsoever about the value or otherwise of believing any particular truth. If Marlowe wrote Hamlet and Johnson believes this, it follows from $\left(\mathrm{TG}^{3}\right)$ neither that this combination is good nor that Johnson's so believing is good. Though $\left(\mathrm{TG}^{1}\right)$ and $\left(\mathrm{TG}^{2}\right)$ might imply $\left(\mathrm{TG}^{3}\right)$, the converse clearly does not hold. It is consistent with $\left(\mathrm{TG}^{3}\right)$ that nothing less than believing every truth is good.

A shortcoming in both $\left(\mathrm{TG}^{2}\right)$ and $\left(\mathrm{TG}^{3}\right)$ is that they fail to make it clear that, when a belief is false, the defect lies with the believer, not the world. That is, the reason it is not good when a subject believes that the sky is falling is not the sky's not 
falling but her believing that it is. ${ }^{6}$ In contrast, $\left(\mathrm{TG}^{1}\right)$ makes it clear that, when a proposition is false, what is not good is its being believed, rather than its being false.

As my introductory remarks indicate, the primary focus of this paper is $\left(\mathrm{TG}^{1}\right)$, and I take it that it is some version of this principle which most of the authors cited above advance. ${ }^{7}$ If the objection I introduce in the following section undermines $\left(\mathrm{TG}^{1}\right)$, it might also undermine $\left(\mathrm{TG}^{2}\right)$, though it does not thereby undermine $\left(\mathrm{TG}^{3}\right)$. However, if I am right that there is no content-independent value in believing a particular truth, one might wonder how there could be content-independent value in believing every truth. Be that as it may, for the remainder, when discussing (TG) and (FB), I shall interpret them in accordance with $\left(\mathrm{TG}^{1}\right)$ and the corresponding version of (FB).

The next matter to address is what kind of value (TG) attributes to true belief. It is common to distinguish different sorts of value, and true belief might have one sort but not others. It is clear that the alleged value of true belief could not be hedonic, aesthetic or moral, not least because that value is supposed to be content-independent. Philosophers frequently suggest that true belief is epistemically valuable (cf. DePaul 2001: 77; Feldman 2000: 683). But this raises thorny issues as to what counts as an epistemic value. Philosophers almost as frequently suggest that what is of epistemic value is what appears valuable from the epistemic 'point of view' or 'perspective' (cf. Alston 1989: 81ff; Baehr 2012: 4). But this in turn raises equally thorny issues as to what counts as an epistemic perspective. Rather than seek to resolve these issues, which is beyond the scope of this paper, I shall trade on the familiarity of the notion of epistemic value and assume that we have some grasp of it. For now, note only that being of epistemic value need not be opposed to being of value simpliciter; on the

\footnotetext{
${ }^{6}$ David (2005a) and Piller (2009) raise versions of this point when discussing the idea that subjects want or desire to believe the truth (cf. n3 above).

${ }^{7}$ Lynch (2005), for example, explicitly endorses $\left(\mathrm{TG}^{1}\right)$.
} 
contrary, a proponent of (TG) might claim that true belief is of value simpliciter in virtue of being of epistemic value. ${ }^{8}$

Next, one might ask whether the value (TG) attributes to true belief is instrumental, that is, valuable only as a means to a valuable end, or final, that is, valuable as an end in itself. Most of those who advance (TG) think that the value of believing the truth is final (which is not to deny that so believing might also be instrumentally valuable). In Horwich's words, 'we should acknowledge that true belief has a non-instrumental value - a value for its own sake' (2010: 66). It is this view which I shall focus on.

Finally, it is important to stress that (TG) should be read as expressing a judgement, not of all-things-considered or overall value, but of pro tanto or prima facie value. If something is prima facie valuable, it has a value which might be defeated (or outweighed, or undercut, or...) in a given circumstance. For example, cycling to work might be prima facie good, insofar as it provides an opportunity for much-needed exercise, is less harmful to the environment than driving, is exhilarating, and so forth, but that goodness might be defeated if cycling to work were to prevent me from getting to the office on time, say, or result in a collision with a bus. In such a situation, cycling to work is not valuable overall but it remains prima facie valuable.

Returning to the case at hand, clearly there are circumstances in which it is not good that a subject believes the truth. For example, Charlie's true belief that he lacks social skills has a detrimental effect on his psychological health and serves only to aggravate the relevant problem. And Lucy's true belief that she won the lottery is irrationally held in the face of all available evidence. In such cases, according to

\footnotetext{
${ }^{8}$ It is consistent with (TG) that things other than true belief possess epistemic value, such as knowledge or understanding. Thus, (TG) does not entail monism about epistemic value.
} 
(TG)'s proponent, the prima facie goodness of believing the truth is defeated by competing considerations.

\section{$3 \quad$ Trivial pursuits}

Recall Malebranche's disparaging remarks on the 'learned' who 'turn their head into a kind of furniture warehouse into which they indiscriminately cram $[\ldots]$ curiosities and antiques, which have no value or solidity' (1997 [1674-1675]: xxxv). These remarks point to a common objection to (TG). Many truths are utterly trivial; to believe them is worthless and so, contra (TG), not good. ${ }^{9}$ Consider every truth about every hair on my head. It is true that this particular hair is $45 \mathrm{~mm}$ and brushed bronze, while this one is $34 \mathrm{~mm}$ and autumn sunset, and so on. While believing these things might do one no harm, would it really be good to believe them? It is hard to see why. Call this, the objection from triviality.

What, one might ask, is it for a truth to be trivial? I do not have an informative (non-trivial!) answer to this question. I shall simply assume that there are some true beliefs which the reader, with both critics and advocates of (TG), recognises as concerning insignificant, unimportant matters, like the truth about the number of threads in my office carpet, to borrow Lynch's example (2005b: 55), or that truth disjoined with an arbitrary number of arbitrary propositions, such as that the moon is made of cheese, or that puddles are puddles, or... I shall add only that a truth can be trivial in certain circumstances and non-trivial in different circumstances. For example, the number of threads in the carpet is of no concern to me but it might matter to Alex,

\footnotetext{
${ }^{9}$ For versions of this point, see David 2005b; Grimm 2008; Heal 1987/88; Sosa 2001.
} 
if Alex were offered one billion dollars to find out how many threads there are in the carpet. $^{10}$

A common response to the objection from triviality is to restrict (TG) and claim that what is good is believing truths concerning matters of 'interest' or 'significance' (cf. Alston 2005: 28; Goldman 2001):

$\left(\mathrm{TG}^{\mathrm{M}}\right)$ For any $p$ : if it matters whether $p$, it is good to believe that $p$ if and only if it is true that $p$.

I shall set $\left(\mathrm{TG}^{\mathrm{M}}\right)$ aside, since to restrict the principle in this way is simply to give up the claim that true belief has content-independent value. The concern of this paper lies with attempts to hold on to that claim in the face of the objection from triviality. ${ }^{11}$

A different move, which Wedgwood proposes (2002: 273), following Chisholm (1977: 14), is to restrict (TG) to those propositions one considers:

$\left(\mathrm{TG}^{\mathrm{C}}\right)$ For any $p$ : if one considers whether $p$, it is good to believe that $p$ if and only if it is true that $p$.

Unlike $\left(\mathrm{TG}^{\mathrm{M}}\right),\left(\mathrm{TG}^{\mathrm{C}}\right)$ still attributes to certain true beliefs content-independent value. The value of believing a truth is conditional upon one's having considered it, but not on what one believes or considers.

Many, perhaps most, beliefs are held or acquired unreflectively or implicitly, and so without consideration. Consider, for example, all the beliefs one acquires through perception. Suppose that certain such beliefs are true. For all $\left(\mathrm{TG}^{\mathrm{C}}\right)$ says, it might not be good to have them. Or suppose that certain such beliefs are false. $\left(\mathrm{TG}^{\mathrm{C}}\right.$ )

\footnotetext{
${ }^{10}$ To say that there are possible circumstances in which it would be good for a subject to believe a truth is, of course, not to say that in the actual circumstances it is good for her to do so (cf. Heal 1987/88).

${ }^{11}\left(\mathrm{TG}^{\mathrm{M}}\right)$ is of little use to teleologists who seek to account for the epistemic norms to which believing is subject by presenting them as specifying the means to securing the relevant value, since those norms do not appear to govern only beliefs concerning interesting or significant matters. For this point, see Grimm 2009. Something similar can be said of $\left(\mathrm{TG}^{\mathrm{C}}\right)$, introduced below.
} 
does not deliver the verdict that it is not good to have them. These points do not show $\left(\mathrm{TG}^{\mathrm{C}}\right)$ to be false but they do suggest that the principle is too weak.

More importantly, it is doubtful that restricting the claim about the contentindependent value of truth to those propositions one considers really speaks to the objection from triviality. If one feels its pull, as all those participating in the debate appear to do, one might well think that, for some trivial truth one considers, believing it is neither better nor worse than not believing it - precisely because it is trivial.

A proponent of $\left(\mathrm{TG}^{\mathrm{C}}\right)$ might reply by reminding us that consideration is a purposive activity which at least in part aims to result in true beliefs. Thus, for one who considers a certain matter, believing the truth concerning it is good, even if that matter is trivial, insofar as so believing satisfies one's aim in considering it.

One might ask how, if a truth is not worth believing, the mere fact that one considers it could make it so. The proposed reply assumes that the value of an end in this case, true belief - derives from the value of pursuing it - in this case, consideration - which is surely to get things back to front. The value of a pursuit is parasitic on the value of its end; in which case, if the end has no value, the pursuit has no value. ${ }^{12}$ Thus, one does not answer the objection from triviality by restricting the claim that true belief is good to those propositions one considers.

The standard response to the objection from triviality is to remind us that, as stressed above, the value (TG) attributes to true belief is prima facie (see Fantl and McGrath 2009: 165-167; Horwich 2010: 59-60; Kvanvig 2003: 41; Lynch 2004a: 501). The fact that some truths are trivial and thus not worth believing does not cast doubt on (TG); it is just that the triviality of a candidate belief defeats the value of its truth.

\footnotetext{
${ }^{12}$ Perhaps there are theories of value according to which this is not so. It would be a cost for the proponent of $\left(\mathrm{TG}^{\mathrm{C}}\right)$ if her defence of it were to rest upon a highly controversial theory of value.
} 
At this point, there is a danger of reaching a standoff between those who hold that there is prima facie value in believing the truth, which is defeated when that belief is trivial, and those who hold that there is no such value at all. To make progress, it is worth thinking about what kinds of considerations might, according to the proponent of (TG), defeat the prima facie value of true belief when that belief concerns a trivial matter. Perhaps she has in mind something like the following line of thought. For finite beings, having any particular belief is at the expense of having others and draws on limited cognitive resources. Thus, the prima facie value of a true belief must be measured against what one might call the cognitive cost of forming and maintaining that belief. While it is good to believe a given truth, doing so comes at cognitive cost and that cost is not worth paying, so to speak, when the truth in question is trivial.

Recall that, because we are finite, all our beliefs come at some cognitive cost. So, the proponent of (TG) who advances the above line of thought must hold that the mere fact that a proposition is true is never enough to make it good (overall) to believe it; for believing that proposition to be good, doing so must bring additional theoretical or practical benefits. It is hard to see the difference between that position and a weaker one according to which true belief is, as such, value-neutral and whether or not there is value in believing a given truth turns on the theoretical or practical importance of that belief, which in turn depends on what it is about, that is, on its content.

Relatedly, the above line of thought presents (TG) as the claim that it is good to believe a given truth, considered apart from the cognitive costs of doing so. But, as Baehr argues, 'the costs are a direct function of certain deep features of our cognitive nature' (2012: 10). In which case, he asks, 'why think that for the judgement in 
question $[(\mathrm{TG})]$ to be true from a ceteris paribus standpoint it must abstract away from the relevant essential features of our cognitive nature?' To put the same point differently, what is of epistemic value is what appears valuable from the epistemic perspective. But that is the perspective of finite beings with limited cognitive resources. So, what is of epistemic value, prima facie or otherwise, cannot be determined apart from facts about such finitude and limitations. Hence, cognitive costs cannot be independent considerations which defeat the epistemic value which true beliefs would otherwise have.

Finally, the story which appeals to cognitive costs underestimates the force of the original objection. Let us simply stipulate that a given believer has plenty of room, as it were, for forming beliefs and so that coming to believe a particular piece of trivia would not be costly for her. It remains hard to see what value there is in her doing so. Suppose that a subject could form a true belief about the colour and length of a particular hair on my head at little to no cost. While it might not be a bad thing were she to do so, it would surely not be a good thing.

Of course, a proponent of (TG) might not share this estimation. Following Horwich (2010: 59n2) and Kvanvig (2008: 209-210), she might point out that God is the 'cognitive ideal'. God is omniscient and so believes all and only truths, including all those about the number of threads in my carpet, the colour and length of each hair on my head, and so on. Since God is omnipotent, these beliefs come at no cognitive cost. And presumably God's omniscience is part of what makes God good. Perhaps this supports the idea that, for any truth, it would be good to believe it were it not for the cognitive costs of doing so.

If God is indeed the cognitive ideal, insofar as God believes all and only truths, this at most supports $\left(\mathrm{TG}^{3}\right)$. As discussed earlier, there is no immediate route from 
$\left(\mathrm{TG}^{3}\right)$ to $\left(\mathrm{TG}^{1}\right)$, the present concern. Furthermore, omniscience is not simply a matter of believing all truths but of knowing all truths. For all I say here, from the fact that a proposition is true, it might follow that it is good to know it; it does not follow from this that it is good to have an attitude toward that proposition which falls short of knowledge. Finally, recall that, on many traditional conceptions, God creates and sustains the universe. Thus, one might think that, for God, no truth is trivial; it does not follow from this that, for the rest of us, no truth is trivial.

Elsewhere, Kvanvig tells a rather different story in defence of (TG) about how the prima facie value of true belief might be weighed alongside other considerations. According to Kvanvig, the goodness of believing a given truth is defeated if it 'doesn’t do much explanatory work for us’ or 'doesn't help our overall understanding of the universe much' (2009: 339). So, the suggestion goes, taking into account only the truth of a proposition, it is good to believe it but, taking into account the fact that it does no explanatory work and does not further our understanding, it is not good to believe that proposition.

Unfortunately, for the proponent of (TG), understood in the way Kvanvig recommends, the principle amounts to the claim that it is good to believe the truth only if doing so brings about some kind of theoretical benefit. But this is precisely to concede that believing the truth is not itself good; what is good is being explanatory or furthering understanding, not being true.

To put the same point differently, to say that some feature is prima facie valuable is to say that it is good for something to possess it unless certain features are present which defeat that value (by outweighing or undercutting it). For example, to say that having a successful career is prima facie valuable is to say that it is good to have a successful career unless it leads to poor health, to strained relations with one's 
immediate family, and the like. But, for Kvanvig, it is good to believe a truth unless certain features are absent — such as being explanatory — which is to say that the goodness of true belief is conditional upon the presence of such good-making features. But this is just to concede that true belief is not itself good. In trying to defend (TG), Kvanvig unwittingly relinquishes it.

At this point, a defender of (TG) might adopt a more offensive, less defensive, approach. To make the objection from triviality, she might complain, is to import foreign considerations to the issues at hand. Specifically, the objection is made from the practical perspective; it is only from that perspective that trivial truths appear not worth believing and, she continues, it is no surprise that the epistemic value so believing possesses does not show up when one adopts it.

This does not get (TG)'s proponent very far. Many of those who advance the objection from triviality think of themselves as precisely adopting the epistemic perspective. Consider:

If you propose an evening memorizing the phone book for Topeka, Kansas, and I decline, have I really missed an opportunity to enrich myself, from an epistemic point of view? (2008: 726; cf. Baehr 2012: 4)

As these remarks show, the objection just does not appear to be one which can only be made from the practical perspective. Setting aside practical considerations, one might say, there seems to be no value in believing the truth about the length and colour of a certain hair on my head. Of course, one might not share this estimation but it does not follow, at least without further ado, that this is because one does not share the perspective from which it is made.

Moreover, the above line of thought seems simply to assume that the epistemic perspective is one from which true beliefs appear valuable, which is to beg the question. Indeed, the issue at hand is in part one concerning how exactly to 
characterise the epistemic perspective - by considering what appears to be of value when adopting it. In which case, that perspective is not a neutral datum to which (TG)'s proponent can appeal in an effort to block the objection from triviality.

In view of this, consider another of Kvanvig's proposals concerning the kinds of considerations that might defeat the prima facie value of true belief. According to Kvanvig, 'We are finite beings, with limited time and resources for enhancing our well-being'. As a result, 'our general interest in enhancing our well-being comes into conflict with our general interest in the truth' (2003: 41; cf. Lynch 2005b: 120). When it does, the value of believing a truth concerning some trivial matter is defeated by the disvalue which results from failing to promote one's well-being (for example, if measuring the hairs on my head so as to form true beliefs as to their lengths were at the expense of eating a healthy meal or spending time working on a project which would further my career).

Kvanvig here assumes that believing trivial truths seems worthless only from the practical perspective or that it is practical considerations which defeat the prima facie value of believing a given truth. This assumption, as we have just seen, is mistaken. Thus, Kvanvig does not take the full measure of the objection from triviality. Suppose that believing a particular trivial truth would not interfere with one's well-being. There is nothing else one could do right now, let us stipulate, but count the number of threads in the carpet in my office. Surely, while it might not be bad to form a true belief about this matter, it would not be positively good to do so. It seems, then, that none of the ways considered here of cashing out the idea that believing the truth possesses prima facie value which is defeated in the case of trivial beliefs are successful; they appear either to give the wrong explanation as to 
why trivial truths are not worth believing or to give up on the very idea that true belief has prima facie value.

In light of the objection from triviality, there is reason to reject (TG). The objection is not, I admit, decisive and perhaps there are further things which a proponent of (TG) might say in response to it. Moreover, the force of that objection and of responses to it depend to some extent on estimations which might not be shared. Rather than pursue these matters further, I shall consider how well-motivated (TG) is. If it lacks motivation, then so does the search for solutions to the above objection.

\section{$4 \quad$ Falsity as bad}

Before moving on, note that I have only challenged one half of (TG). Still standing is:

(TG') For any $p$ : it is good to believe that $p$ only if it is true that $p$.

I accept (TG'). It seems right that, if it is not true that Thomas Pynchon wrote White Noise, it is not good to believe it. Indeed, I shall argue for a stronger principle, which implies (TG'), namely:

(FB) For any $p$ : it is bad to believe that $p$ if and only if it is false that $p$. Though superficially similar to (TG), this principle is quite distinct. Since it is true that camellias are ericaceous, it follows from (TG) that it is good to believe that camellias are ericaceous, while (FB) only implies that it is not bad to do so. Since it is false that roses are ericaceous, it follows from (FB) that it is bad to believe that roses are ericaceous, while (TG) only implies that it is not good to do so. That the difference between (TG) and (FB) makes a difference will become apparent in the discussion that follows. ${ }^{13}$

\footnotetext{
${ }^{13}$ Replacing (TG) with (FB) has implications for the teleological approach to epistemic norms. If she accepts (FB), a teleologist should present epistemic norms as rules which specify the means, not to securing something of value, but to avoiding something of disvalue, namely, false belief. This would seem to commit her to the view that epistemic norms involve permissions or negative obligations-one
} 
Like (TG), (FB) is to be read as expressing a judgement of prima facie value or, rather, disvalue. Though it is prima facie bad to believe falsely that one is a likely candidate for a certain job, it might be good overall so to believe if doing so increases one's confidence, which thereby helps one to secure the job. Likewise, though it is prima facie not bad to believe truly that one holds a winning lottery ticket, it might be bad overall if the belief is irrationally held in the face of statistical evidence. ${ }^{14}$

\section{$5 \quad$ Millian considerations}

In this section, I shall examine certain informal considerations adduced in support of (TG) on the basis of what one might call a 'Millian' strategy, namely, offering as evidence for what is valuable claims about what is valued. ${ }^{15}$ One might have qualms about such a strategy but, for present purposes, I shall grant its legitimacy and instead suggest that the relevant evidence points, not to (TG), but to (FB). In the next section, I shall arrive at the same verdict by examining more principled considerations.

In support of (TG), Lynch writes:

Nobody likes to be wrong. If anything is a truism, this is. And it suggests that we value believing the truth. Roughly speaking, we think it is good to believe the truth, and not to believe the false. (2004a: 499)

In response, consider how one should understand the claim that nobody likes to be wrong. It might mean: if one believes a certain proposition, one dislikes that

\footnotetext{
may believe that $p$ if one has evidence that $p$, for example, or one should not believe that $p$ if one has evidence that not- $p$ - but not positive obligations - for example, one should believe that $p$ if one has evidence that $p$. For arguments in support of the view that there are no positive epistemic obligations, see Feldman 2000: §2; Nelson 2010: 83-102; Whiting 2012.

${ }^{14}$ It is important to stress that in the previous section I did not object to the distinction between prima facie and all-things-considered value, or to bringing that distinction to bear on principles such as (TG), but only to the suggestion that appealing to that distinction saves (TG) from the objection from triviality. Hence, it is legitimate, when discussing (FB), to appeal to that distinction to account for cases like those just mentioned.

${ }^{15} \mathrm{Cf}$. 'The sole evidence it is possible to produce that anything is desirable, is that people do actually desire it' (Mill 1998 [1861]: 81).
} 
proposition's being false. But this attitude seems childish or stubborn. ${ }^{16}$ Maybe some of us have such an attitude toward their beliefs but it is hardly a truism that everybody does. And, insofar as we should not have that attitude, it provides no support for claims about what is desirable or valuable.

Perhaps instead the claim that nobody likes to be wrong should be understood to mean: one dislikes believing a proposition if it is false. That seems right. But it does not follow, as Lynch claims, 'that we value believing the truth' in a sense that would support (TG). Suppose that I dislike not winning marathons, since I find it embarrassing. Does it follow that I like to win? No - perhaps I find the attention that involves equally embarrassing. I prefer to come somewhere in the middle or not to race at all. Likewise, from the fact that I do not like to believe a proposition when it is false, all that follows is that I disvalue false belief, not that I value true belief. These are not equivalent attitudes. A person who values the truth will, other things being equal, seek it out, but a person who disvalues the false might forgo believing altogether.

Nor does it follow from the truism, as Lynch suggests, that we think it good 'not to believe the false'. Suppose I disvalue the false, in the sense that, if a proposition is false, I think it is bad to believe it. With respect to not believing that proposition, I might only think that it is not bad, not that it is good. Something can fail to be bad without being good.

\footnotetext{
${ }^{16}$ I am indebted to David (2005b) and Piller (2009) here, who make similar points with respect to a slightly different claim (cf. n6 above). Note that Piller discusses (2009: 205-206) the above remarks by Lynch but sees no satisfactory way of interpreting the alleged truism. I shall offer one such way in a moment.
} 
So, Lynch's truism does not establish that we take true belief to be good.

Nonetheless, it does point to the superficially similar thought which (FB) embodies, namely, that we take false belief to be bad. ${ }^{17}$

One might wonder if I am placing too much weight on Lynch's choice of example. Doesn't 'Everybody likes to be right' equally express a truism, one which points to $(\mathrm{TG})$ ?

In response, consider how one should understand the claim that everybody likes to be right. It might mean: for any truth, a subject desires or thinks it good to believe it. So understood, however, the claim seems false, not truistic. ${ }^{18}$ As we have seen, unless a proposition concerns a matter of importance or significance, we do not desire or think it good to believe it.

Perhaps the claim that everybody likes to be right should be understood to mean: if one believes a certain proposition, one desires or thinks it good for that proposition to be true. But this attitude looks like one of dogmatism. ${ }^{19}$ Maybe some of us have such an attitude toward some of our beliefs but it is hardly a truism that everybody does. And, insofar as we should not have that attitude, it provides no support for claims about what is desirable or valuable.

Perhaps the claim should be understood to mean: if $p$, one thinks it preferable to believe that $p$ than to believe that not- $p$. So understood, I accept the claim, but it points to (FB), not (TG). That one thinks it undesirable to believe falsely suffices to explain the preference.

\footnotetext{
${ }^{17}$ Admittedly, this consideration supports only the claim that it is bad to believe a proposition if it is false, not the claim that it is bad to believe a proposition only if it is false. Nonetheless, some of the other considerations I discuss in due course support the latter claim.

${ }^{18}$ Of course, Lynch's original claim ('Nobody likes to be wrong') establishes at most a presumption in favour of (FB); it might also turn out to be wrong. Since the focus of the present section is the considerations which motivate philosophers to advance (TG) and its kin - in the face of the objection from triviality - I shall postpone this matter until later.

${ }^{19}$ Again, I am indebted here to David (2005b) and Piller (2009).
} 
Consider next Kvanvig's case in support of (TG). He invites us to imagine a situation in which one's beliefs are 'empirically adequate', that is, they 'will never be revealed to be false in virtue of some false prediction' one makes on the basis of them 'about the course of experience'. Empirically adequate beliefs have the same practical utility as true beliefs. Nonetheless, Kvanvig continues, were one to learn 'that one's beliefs are empirically adequate but untrue' this would generate 'a negative affective sense of having been duped' (2003: 39-42). ${ }^{20}$

This seems right but one must ask what it shows. Suppose that one does not like the idea of having empirically adequate but untrue beliefs. It follows that the disvalue one attaches to false beliefs defeats any value one attaches to empirically adequate beliefs. This does not show that one values true belief but only that one disvalues false belief. Hence, like Lynch's, Kvanvig's considerations do not support (TG) but (FB).

Lynch appeals to similar ideas when pointing out that, if one had to choose 'between living in the actual world or the world created for us by Descartes' imaginary evil demon', one would choose the actual world, even though one's beliefs in the demon world would have the same instrumental value as they do in the actual world (2004a: 502-503). One might accept this but it does not establish what Lynch takes it to. Reflection on the scenario shows that we disvalue believing falsehoods or, as Lynch himself puts it, that we 'find the prospect of being undetectably wrong [...] disturbing'. It does not, however, show what Lynch needs it to show, namely that we value believing the truth, no matter what it concerns. So, reflection on radical sceptical scenarios points, contra Lynch, to (FB) not (TG). Lynch appears to treat

\footnotetext{
${ }^{20}$ To pick up on a previous issue, Kvanvig's remarks might seem to be suggesting that, on discovering that one's (empirically adequate) belief that $p$ is false, one has a con-attitude toward its being the case that not- $p$. I shall assume, however, that he is suggesting that, on discovering this, one has a conattitude toward one's believing that $p$.
} 
disvaluing falsity and valuing truth as one and the same but it should be clear by now that to do so is mistaken.

Lynch makes an additional observation:

Unless truth has more than instrumental value, there would be nothing wrong with believing trivial falsehoods, such as the proposition that 100 gazillion trillion is the highest number. But as Bernard Williams puts it, the falsity of a proposition is in fact a terminal objection to believing it. (2004a: 502; cf. Williams 1973: ch. 9)

This is an observation to which I am sympathetic but Lynch's principle does not capture it. (TG) only tells us that believing a falsehood is not good, not that it is bad. The Williams point supports (FB), not (TG).

Rather than appeal directly to our attitude toward true belief in support of (TG), Pritchard appeals to our attitude toward something which involves true belief, namely, authenticity:

The kind of life we want to lead is an authentic life - one that is in touch with the world - where the relationships that we form are genuine and the achievements we strive for are real $[\ldots]$ It is because we value authenticity that we value truth. (2010: 155)

The line of thought here is that believing the truth is a constitutive part of an authentic existence. Since authenticity is valuable, true belief is valuable, as (TG) states.

One might challenge this by denying that authenticity is good, or that it requires that one's beliefs be true, but I shall grant Pritchard both claims. The line of thought does not in any event show that true belief is good for the simple reason that, though true belief might be necessary for authenticity, it is insufficient. To appreciate this, consider the following. Archie draws his bow and shoots an arrow. ${ }^{21}$ The arrow is blown off course by a gust of wind but another gust blows it back on course and it

\footnotetext{
${ }^{21}$ Sosa is responsible for examples of this sort (see 2007: 22).
} 
hits its target. Archie's performance is successful but it is not an authentic achievement, since Archie's hitting the target was due to manipulation and luck - he could easily have been missed. Now consider René. Whenever René is about to form a belief, an evil demon flicks a coin. If the coin lands heads, René gets a true belief; if it lands tails, René gets a false belief. To date, the coin has always landed heads and so René has many beliefs, all of which are true. Like Archie's shot, René's beliefs are accurate and on target, so to speak, but due to manipulation and luck - they could easily have been false. René's perspective on the world is inauthentic - it is not, one might say, his own - and so the life he leads in light of it is inauthentic too.

It seems that having true beliefs is consistent with both authenticity and inauthenticity. So, if authenticity is good, the fact that believing the truth is a constitutive part of authenticity does not reveal believing the truth to be good when the other conditions for authenticity are not met.

In contrast, though believing falsehoods is not necessary for inauthenticity, as the case of René shows, it is arguably sufficient. If René's beliefs are false, perhaps due to the manipulation of an evil demon, he does not have a grip on reality and the life he leads in light of them is inauthentic. And that suggests that believing falsehoods is bad, insofar as inauthenticity is bad.

Needless to say, there is a lot more to be said about what makes for (in)authenticity and a full exploration of the issue is beyond the scope of this paper. But appearances suggest that reflection on authenticity points not to (TG) but to (FB).

While I do not pretend to have offered an exhaustive survey of the literature, none of the considerations above favour the idea that true belief is good, although all favour the idea that false belief is bad. Lynch, Kvanvig, and Pritchard either ignore the latter idea or run it together with the former. 
There are further Millian considerations which suggest that we think it bad to believe the false while we do not think it good to believe the truth, and which thereby support (FB) over (TG). ${ }^{22}$ Suppose that it is false that $p$ and true that $q$. Suppose further that one is faced with two options - not believing that $p$ and not believing that $q$, or believing that $p$ and believing that $q$. The first option, having no false belief but no true belief either, is surely preferable to the second, having a true belief but also a false belief. This indicates that truth and falsity do not, so to speak, cancel each other out, that we take believing a falsehood to be bad in a way that we do not take believing a truth to be good. Alternatively, suppose that one is faced with the following two options - believing that $p$ and believing that not- $p$, or neither believing that $p$ nor believing that not- $p$. Surely, the second option, abstaining from belief, is preferable to the first, having contradictory beliefs. The acquisition of a true belief does not compensate for the acquisition of a false one. The idea that believing falsely is bad while believing truly is not good makes sense of this.

The considerations in the previous paragraph show that our evaluations of true belief and false belief, when considered apart from their subject-matter, are asymmetrical. This seems to provide strong Millian evidence for (FB) over (TG).

\section{A non-Millian consideration}

In this section, I shall focus on a more principled consideration which Lynch offers in support of (TG), appealing to the platitudinous connection between true belief and correct belief:

Just as we evaluate actions as correct or incorrect, 'true' and 'false' are used to evaluate beliefs as correct or incorrect [... This suggests] that truth is a property that it is good for beliefs to have. Since propositions are the contents of beliefs, and it is the

\footnotetext{
${ }^{22}$ This paragraph draws upon Sorensen 1988: 36-37.
} 
content of a belief, not the act of believing, that is true, we can also say that truth is the property that makes a proposition good to believe, or alternatively, that a belief's being true is good. (2004a: 499)

The line of thought is as follows. Correctness is an evaluative notion. Beliefs are correct or incorrect just insofar as they are true or false respectively. So, truth is an evaluative notion, which picks out a property that is good for belief.

One might represent this argument as progressing from the following platitude:

(C) For any $p$ : it is correct to believe that $p$ if and only if it is true that $p$.

to:

(TG) For any $p$ : it is good to believe that $p$ if and only if it is true that $p$. This argument is too quick. In the first instance, one might challenge the assumption that whether something is correct is an evaluative matter. But I shall grant to Lynch that the claim that something is correct is, or implies, an evaluative claim; what I shall deny is that it is, or implies, a positive evaluative claim.

Something's being correct is not always a good thing, though no doubt it sometimes is. For example, the claim that the use of a certain epithet is politically correct should surely not be understood to imply that it would be good to use that epithet but, at most, that it would not be bad to do so (perhaps because it would cause no offence). Likewise, to say that someone filled out a form correctly is not to suggest that she filled it out well, though it is does appear to suggest that she did not fill it out badly. Very roughly, to say that something is correct is to say it meets a certain standard. And the fact that something meets a certain standard implies that it is not deficient, that it is adequate or passable, not that it is positively good, as the examples testify. If this is right, then the transition from the platitudinous (C) to (TG) is unwarranted. Nonetheless, a similar transition is warranted. 
The claim that something is incorrect is, or implies, a negative evaluative claim. Something's being incorrect is, other things being equal, a bad thing. For example, the claim that the use of a certain epithet is politically incorrect should surely be understood to imply that it would be bad to use that epithet (perhaps because it would cause offence). Likewise, to say that someone filled out a form incorrectly is to suggest that she filled it out poorly or in a bad way. Very roughly, to say that something is incorrect is to say it fails to meet a certain standard. And the fact that something fails a certain standard implies that it is deficient, that it is inadequate or unacceptable, as the examples testify. Note that (TG) fails to capture the idea that incorrectness is disvaluable. Suppose that it is false that $p$, and so incorrect it believe it. All that follows from (TG) is that it is not the case that it would be good so to believe, not that it would be bad.

So, the platitude about correctness does not support Lynch's claims about the goodness of true belief. By way of contrast, consider an argument from:

(C) For any $p$ : it is correct to believe that $p$ if and only if it is true that $p$.

to:

(IC) For any $p$ : it is incorrect to believe that $p$ if and only if it is false that $p$. to:

(FB) For any $p$ : it is bad to believe that $p$ if and only if it is false that $p$. This preserves the link between what is incorrect and what it would be bad to do, and keeps apart what is correct and what it would be good to do. ${ }^{23}$

\footnotetext{
${ }^{23}$ For a complementary discussion, see Whiting 2010.
} 


\section{$7 \quad$ Trivial pursuits revisited}

I have argued that neither the Millian nor the more principled considerations support (TG); instead, both support (FB). One might, however, wonder if a version of the objection from triviality succeeds against (FB). In this section, I shall suggest that it does not.

In the first instance, note that, for any one of the indefinite number of trivial truths, (FB) implies that it is not bad to believe them. This, I venture, is the right verdict. Typically, we think that (other things being equal), while it is not good to believe trivial truths, there is no harm in doing so. To say that $\varphi$ ing is trivial is only to say that there is no value in $\varphi$ ing, not that there is disvalue in $\varphi$ ing. Drumming one's fingers might be a trivial activity, and so of little worth, but it is not a bad thing to do. So, the fact that (FB) suggests that it is not bad to believe trivial truths counts in support of it, not against it.

Nonetheless, one might object to (FB) as follows. If it is not good to believe trivial truths, it is not bad to believe trivial falsehoods. Suppose that I believe that I have 100,046 hairs on my head, when in fact I have 100,047. (FB) is mistaken, the objection continues, since it suggests that it would be bad to have this false belief, when it is neither here nor there.

However, unlike the objection to (TG) from trivial truths, the objection to (FB) from trivial falsehoods lacks force. It seems bad to believe a falsehood, even when it concerns a trivial matter. If I offered to fill your head with trivial truths, you would surely decline. In contrast, if I offered to rid your head of trivial falsehoods, you would surely accept.

Of course, this is not an argument. But I have more on my side. Above I surveyed numerous Millian and non-Millian considerations - none were found to 
support (TG) and all were found to support (FB). Cumulatively, if not individually, they provide a strong case for the claim that it is bad to believe falsely, no matter what the subject-matter.

Someone might continue to insist that it is not bad to believe trivial falsehoods. But merely to insist in this way is not to advance the argument. The onus is on the opponent of (FB) to show that the many considerations which seem to support the principle in fact do not, as I did with respect to (TG). Until she does so, there remains a presumption in favour of $(\mathrm{FB})$.

\section{Conclusion}

Some philosophers claim that, in general, true belief is, independent of its content, good. I have suggested that this is mistaken. However, I suspect that those philosophers have confused that claim with another which sounds very much alike, though it is quite distinct, a claim which has a lot more going for it, namely that, in general, false belief is, independent of its content, bad.

It was not my aim to prove that it is bad to believe what is false or to disprove that it is good to believe what is true but rather to offer a reminder that these are two quite distinct claims which need to be kept apart, to make room in doing so for accepting one without accepting the other, and to make something of a case for thinking that the first, not the second, is the one to go with. Adding more and more to the stock of true beliefs does not make the world a better place, I have suggested, but removing more and more from the stock of false beliefs does.

If it is indeed the case that believing the truth is not valuable in the way that believing the false is disvaluable, it would be worthwhile investigating why by exploring in more depth this asymmetry, and it would be equally worthwhile 
considering further its consequences and explanatory import. Such tasks are for another occasion.

\section{References}

Alston, W. 1989: Epistemic Justification. Ithaca, NY: Cornell University Press.

—. 2005: Beyond Justification. Ithaca: Cornell University Press.

Baehr, J. 2012: Credit Theories and the Value of Knowledge. Philosophical Quarterly 62: 1-22.

Chisholm, R. 1977: Theory of Knowledge, $2^{\text {nd }}$ ed. Englewood Cliffs, NJ: Prentice Hall. DePaul, M. 2001: Value Monism in Epistemology. Knowledge, Truth, and Duty, ed. M. Steup. Oxford: Oxford University Press.

David, M. 2005a: On 'Truth is Good'. Philosophical Books 46: 292-301.

—. 2005b: Truth as the Primary Epistemic Goal. Contemporary Debates in Epistemology, ed. M. Steup and E. Sosa. Oxford: Blackwell. Engel, P. 2009: Pragmatic Encroachment and Epistemic Value. Epistemic Value, ed. A. Haddock, A. Millar and D. Pritchard. Oxford: Oxford University Press.

Fantl, J. and McGrath, M. 2009: Knowledge in an Uncertain World. Oxford: Oxford University Press.

Feldman, R. 2000: The Ethics of Belief. Philosophy and Phenomenological Research 60: 667-695.

Goldman, A. 1986: Epistemology and Cognition. Cambridge, MA: Harvard University Press.

—. 2001: The Unity of the Epistemic Virtues. Virtue Epistemology, ed. A. Fairweather and L. Zagzebski. Oxford: Oxford University Press. 
Grimm, S. 2008: Epistemic Goals and Epistemic Values. Philosophy and Phenomenological Research 77: 725-744.

—. 2009: Epistemic Normativity. Epistemic Value, ed. A. Haddock, A. Millar and D. Pritchard. Oxford: Oxford University Press.

Heal, J. 1987/88: The Disinterested Search for Truth. Proceedings of the Aristotelian Society 88: 97-108

Horwich, P. 2010: Truth—Meaning—Reality. Oxford: Oxford University Press.

James, W. 1995 [1907]: Pragmatism. New York: Dover.

Jones, W. 1997: Why Do We Value Knowledge? American Philosophical Quarterly 34: 423-439.

Kvanvig, J. 2003: The Value of Knowledge and the Pursuit of Understanding. Cambridge: Cambridge University Press.

—. 2008: Pointless Truth. Midwest Studies in Philosophy 32: 199-212.

—. 2009: Responses to Critics. Epistemic Value, ed. A. Haddock, A. Millar and D.

Pritchard. Oxford: Oxford University Press.

Loewer, B. 1993: The Value of Truth. Philosophical Issues 4: 265-280.

Lynch, M. 2004a: Minimalism and the Value of Truth. Philosophical Quarterly 54: 497-517.

—. 2004b: True to Life. Cambridge, MA: MIT Press.

—. 2005: Replies to Critics. Philosophical Books 46: 331-342.

Malebranche, N. 1997 [1674-1675]: The Search after Truth, ed. trans. T. Lennon and P. Olscamp. Cambridge: Cambridge University Press.

McHugh, C. 2012: The Truth Norm of Belief. Pacific Philosophical Quarterly 93: 830.

Mill, J. S. 1998 [1861]: Utilitarianism, ed. R. Crisp. Oxford: Oxford University Press. 
Morris, M. 1992: The Good and the True. Oxford: Oxford University Press.

Nelson, M. 2009: We Have No Positive Epistemic Duties. Mind 473: 83-102.

Piller, C. 2009: Desiring the Truth and Nothing but the Truth. Noûs 43: 193-213.

Pritchard, D. 2010: What is this Thing Called Knowledge?, $2^{\text {nd }}$ ed. London: Routledge.

Putnam, H. 1981: Reason, Truth and History. Cambridge: Cambridge University

Press.

Railton, P. 1994: Truth, Reason, and the Regulation of Belief. Philosophical Issues 5: $71-93$

Riggs, W. 2002: Reliability and the Value of Knowledge. Philosophy and Phenomenological Research 64: 79-96.

Schantz, S. 2007: Why Truth is Not an Epistemic Concept. Truth and Speech Acts, ed.

D. Greimann and D. Siegwart. London: Routledge.

Sorensen, R. 1988: Blindspots. Oxford: Oxford University Press.

Sosa, E. 2001: For the Love of Truth? Virtue Epistemology, ed. A. Fairweather and L. Zagzebksi. Oxford: Oxford University Press.

—. 2007: Virtue Epistemology: Apt Belief and Reflective Knowledge. Oxford: Oxford University Press.

Wedgwood, R. 2002: The Aim of Belief. Philosophical Perspectives 16: 267-297.

Whiting, D. 2010: Should I Believe the Truth? dialectica 64: 213-224.

—. 2012: Does Belief Aim (Only) at the Truth? Pacific Philosophical Quarterly 93: $279-300$.

Williams, B. 1973: Problems of the Self. Cambridge: Cambridge University Press. Zagzebski, L. 2003: The Search for the Source of Epistemic Good. Moral and Epistemic Virtues, ed. M. Brady and D. Pritchard. Oxford: Blackwell. 